\title{
Evaluation of person-centred care after hip replacement-a controlled before and after study on the effects of fear of movement and self-efficacy compared to standard care
}

\author{
Lars-Eric Olsson ${ }^{1,2,3^{*}}$, Elisabeth Hansson ${ }^{1,3}$ and Inger Ekman ${ }^{1,2}$
}

\begin{abstract}
Background: The goal of total hip arthroplasty (THA) is optimal pain relief and a normalized health-related quality of life. Anxious patients describe more pain and more difficulties than non-anxious patients during rehabilitation after THA. The aims of the present study were twofold: (1) to identify vulnerable patients using the general self-efficacy scale (GSES) and the Tampa scale for Kinesiophobia (TSK), and (2) to evaluate if person-centred care including the responses of the instruments made rehabilitation more effective in terms of shortening hospital length of stay.

Methods: The design of the study was quasi-experimental. Patients scheduled for THA, a control group $(n=138)$ and an intervention group $(n=128)$ were consecutively recruited. The intervention was the provision of person-centred care which was designed to reduce the negative effects of low self-efficacy and high levels of pain-related fear of movement.

Results: Patients with low GSES in the intervention group had shorter length of stay (LoS) by 1.6 days $(95 \% \mathrm{Cl}$ 0.16-3.15) $p$-value 0.03. Patients with high TSK in the intervention group had shorter LoS by 2.43 days $(95 \% \mathrm{Cl}$ $0.76-4.12) p$-value 0.005 . For patients who had both, the reduction of LoS was 2.15 days (95\% Cl $0.24-4.04$ ) $p$-value 0.028 .

Conclusions: The GSES and the TSK instrument were found useful as tools to provide information to support patients which reduced the LOS by 1.67 days in the whole intervention group ( $95 \% \mathrm{Cl} 0.72-2.62)$ p-value 0.001 . More importantly, vulnerable patients such as ASA group 3 probably gained the most from the extra support, they had a reduction with 6.78 days $(95 \%$ Cl 2.94-10.62) p-value 0.001 .

Keywords: Person-centred care, Person-centered care, General self-efficacy, Tampa Scale of Kinesiophobia, ASA classification, Total hip replacement, Rehabilitation, Health plan, Planned surgery management, Nursing care

Abbreviations: ASA classification, American society of anaesthetists' classification; gPCC, Gothenburg person-centered care; GSES, General self-efficacy; LoS, Length of stay (in hospital); RN, Registered nurse; THA, Total hip arthroplasty; TSK, Tampa scale of kinesiophobia
\end{abstract}

\footnotetext{
* Correspondence: lars-eric.olsson@gu.se

${ }^{1}$ Institute of Health and Care Sciences, Sahlgrenska Academy, University of

Gothenburg, Box 457SE 40530 Gothenburg, Sweden

${ }^{2}$ Gothenburg Centre for Person-Centred Care (GPCC), University of

Gothenburg, Gothenburg, Sweden

Full list of author information is available at the end of the article
} 


\section{Background}

\section{Person-centred care}

Today, person-centred care is widely advocated as an important component of care in varied contexts $[1,2]$. A key element in person-centred care is the dialogue between the health care professional and the patient: a dialogue with the patient that emphasizes shared decision-making as opposed to talking to (or informing) the patient [3]. The aim of this dialogue is to come to a mutual understanding and agreement of the planned care while medical decisions as always remain the physician s responsibility. This is the first step of personcentred care and the foundation for the partnership that commonly results in an individualized health plan formulated by the health care professional and the patient together (relatives are often involved as well). The health plan includes both short-and long-term goals for the patient along with the actions needed to reach each goal. The plan is a "living" document specific to each patient, in which the goals and actions are tracked and revised over time. In earlier controlled studies the implementation of person-centred care shortened hospital length of stay $(\mathrm{LoS})$ by 30-50\%, significantly reduced uncertainty concerning illness and treatment, and decreased the number of medical complications observed [4-7]. In addition, a recent randomised controlled trial demonstrated significant increased self-efficacy after implementation of person-centred care in primary care [8]. Consequently the present discussion is not whether person-centred care should be implemented in hospital wards and primary care settings or not, but rather to refine and make it even more useful and effective.

\section{Self-efficacy}

Self-efficacy can be described as confidence in one's ability to cope $[9,10]$. Effective patient self-management needs to address patients' confidence in their ability to perform specific activities rather than just convincing them of the value of such activities [11]. The correlation between self-efficacy and rehabilitation outcomes in patients with chronic pain was found to be an important component of therapy [12]. A relationship between self-efficacy and pain self-management and coping strategies was also found in community residents with chronic pain [13]. Self-efficacy was shown to be more important than pain intensity and duration in determining disability among patients with chronic musculoskeletal pain $[14,15]$.

Bandura claims that efficacy expectations determine how much effort a person will expend and how long he or she will remain committed when resistance is encountered (Bandura 1997). Thus, self-efficacy is an important aspect in rehabilitation when patients are put in unfamiliar situations that challenge their ability to care for themselves.

\section{Fear of movement}

Pain is a salient feature and one of the main factors leading to variable outcomes after surgery [16]. The available literature on the topic provides strong evidence of the influence of catastrophizing on emotional, functional, and physiological responses to pain [17]. During the first 1 or 2 days after Total hip arthroplasty (THA) surgery, the postoperative pain intensity can be described as "the worst imaginable" and may be associated with fear and a feeling of faintness [18-20]. Such pain can invoke a fear of movement, which has been shown to partially mediate the effects of pain intensity on disability at the onset of lower back pain [21]. Fear and avoidance of activity play a role in fostering disability in whiplash-associated disorders, and fear reduction produces a significant effect on outcomes [22]. A more complete understanding of patients' experience of pain gained through validated measuring tools could lead to the optimization of patient care [16].

Patients can respond to fear of movement in one of two ways: they can choose to confront the situation or to avoid it. Confrontation leads to reduced fear, while avoidance will increase the fear. Pain-induced avoidance behaviour has two components: the avoidance of pain itself and the avoidance of painful activities [17]. Those who confront situations associated with pain experience less frequent pain, a shorter duration of pain, less fear of pain, and less fear of injury than those who avoid the same situations $[23,24]$. Accordingly, the TSK may be a tool for preoperative assessment because it provides information about the levels of support and pain relief needed.

\section{Total hip arthroplasty (THA)}

The goal of THA is optimal pain relief and an essentially normalized health-related quality of life. In most cases, the need for THA is related to osteoarthritis of the hip. When pain or functional limitations become moderate to severe, THA is indicated.

The current orthopaedic procedures are extremely effective, but patient rehabilitation to functional daily life can be challenging for health care professionals. Reportedly, anxious patients describe more pain and are less satisfied with pain relief compared to patients who are not anxious; therefore, anxious patients may experience more difficulties during rehabilitation after THA $[25,26]$. Anxiety has also been found to correlate with a lower health-related quality of life [27]. Thus, improving self-efficacy and reducing fear of movement among patients who undergo THA are important goals for health care professionals. 
We hypothesized that low self-efficacy and high levels of pain-related fear of movement have a negative effect on rehabilitation after THA. We also hypothesized that these negative effects could be reduced by personcentred care. The aims of the present study were twofold: (1) to identify vulnerable patients using the general self-efficacy scale and the Tampa scale for Kinesiophobia and (2) to evaluate if person-centred care including the responses of the instruments made rehabilitation more effective in terms of shortening hospital length of stay after THA.

\section{Methods}

Between September 2010 and November 2012, 266 patients admitted for planned primary THA were enrolled in the study from two designated Swedish orthopaedic departments, one in a county hospital and one in a university hospital. Detailed methods have been described elsewhere [28]. Briefly, the study had a quasi-experimental, controlled, before-and-after design. A control group $(n=138)$ were consecutively recruited between the $20^{\text {th }}$ September 2010-1 $1^{\text {st }}$ March 2011 and an intervention group $(n=128))$ were consecutively recruited between the $12^{\text {th }}$ December 2011$12^{\text {th }}$ November 2012. Patients' were included if they were scheduled for THA, able to complete the questionnaires, and willing to participate (Fig. 1).

\section{Standard care}

During the examination at the out-patient clinic, all patients were examined by a physician and a RN. The patients answered questionnaires about their living circumstances, physical abilities and filled out surveys such as the GSES, TSK. They received standardized information including peri-operative routines and postoperative training based on hip replacement patients in general. Thus, they were all told that the expected LoS would be 4-5 days not considering the individual patients resources. All oral information was the same as in the written booklet which all patients got in order to have the possibility to repeat the information.

\section{The intervention}

The patients in the intervention group did not receive standardized information, instead, all information was based on their own prerequisites. Evidence-based guidelines, clinical knowledge and patients' individual prerequisites were combined with forming a partnership with professionals. The first step in establishing the partnership was for a RN specialized in surgical care to obtain a narrative from each patient, covering the patient's everyday life, resources, motivation, and goals; patients were also asked to fill out the General Self-efficacy (GSES) and Tampa scale of kinesiophobia (TSK) questionnaires. Next, the RN made a tentative, detailed gPCC health plan based on the narrative, the medical examination, and the self-reported results of the GSES and TSK surveys. The gPCC health plan specified each patient's short-and long-term goals, resources, special needs, and plan for recovery after discharge. It also included a predicted hospital LoS based on individualised data. The tentative health care plan was included in the letter provided to the patient at the outpatient clinic appointment 2 weeks before surgery. The health plan was discussed with the patient and finalized when an agreement was reached between the professionals and the patient.

When the patient was admitted to the ward the day before surgery, the RN at the ward confirmed with the patient that the plan still was valid. The nurses and physiotherapists were encouraged to be aware of each patient's GSES and TSK from the beginning and to act on it. The patients
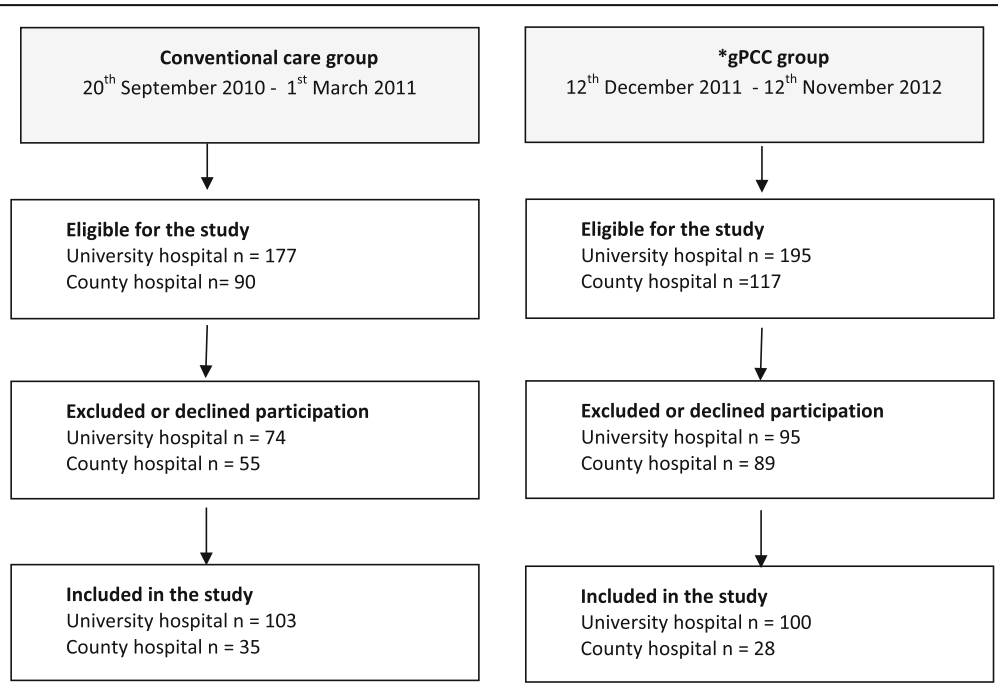

Fig. 1 Study flow chart. * gPCC: Gothenburg person-centred care 
were helped to familiarise themselves in the situation and to achieve their personal goal by emphasising their personal resources and capabilities documented in the health plan. We hypothesized that if the patients were aware of that the nurses new of their personal concerns, their confidence would be strengthened. Pain and fear interact in a negative way and usually we only target pain although targeting both probably is more effective. The nurses facilitated for the patients to describe their concerns and discussed this with them. Some patients based their concerns on troublesome stories they heard, or had misunderstood something while others just felt an anxiety and fear in general. For patients with high fear of motion they were encouraged to talk about their reason for fearing movement. Some patients for example believed the prosthesis needed to settle before it could be treaded on while others interpreted the pain as a sign that something was wrong. Some patients thought the training was rushed so they could be discharged earlier. For all patients in the intervention group it was very important that a rapid recovery was the safest way and would give the best results for them.

\section{Instruments}

\section{General self-efficacy scale (GSES)}

The GSES scale consists of 10 items rated on a fourpoint Likert scale as follows: $1=$ not at all true, $2=$ hardly true, $3=$ moderately true, $4=$ exactly true. In this study, we used the Swedish version of the GSES [29]. The cut-off for low self-efficacy in the present study was set at $\leq 30$ points based on the mean value from the database available at the GSES home page, which includes 19,896 values with a mean of 29.6 points [30]. In case of missing responses, we replaced up to two missing responses with the median value at the individual level [30].

\section{Tampa Scale for Kinesiophobia (TSK)}

The TSK is one of the most frequently used measures for fear of movement [23]. We used the validated Swedish version of the TSK instrument in this study [31]. The TSK scale consists of 17 items rated on a four-point Likert scale with scoring alternatives ranging from'strongly disagree' to'strongly agree.' Values for the 17 sub-questions were summed to yield a total value, which could range between 17 and 68 . The values for questions $4,8,12$, and 16 were reversed before summation. The measured margin of error has been estimated as 3 points: that is, a value between 34 and $40(37 \pm 3)$ [32]. In the present study, for high fear of movement the cut off was set at $\geq 40$; we replaced up to two missing responses with the median value at the individual level.

\section{American Society of Anesthesiologists" classification system (ASA)}

The ASA classification system, which comprises six categories, is used worldwide for assessing the medical fitness of patients before surgery [33]. Patients scheduled for planned surgery commonly belong to one of three categories: (1) healthy, (2) mild systemic disease, or (3) severe systemic disease. The patients in this study were classified by the anaesthesiologist responsible for anaesthetizing patients during the surgical procedure.

\section{Outcomes}

The primary endpoint of the study was the number of days spent in the hospital relative to the self-rated GSES and TSK scores. The hospital LoS was compared between the control group and the intervention group for patients scoring $\leq 29$ on the GSES and/or $\geq 40$ on the TSK. The relation between LoS and ASA category was also studied.

\section{Statistics}

An audit of hospital records showed the combined mean hospital LoS from the two departments for the year 2009 was 7.4 days (SD 5.01). We decided to use the mean LoS from the control group (7.01) for our power analysis, and we estimated that 99 patients would be required in each group to achieve $80 \%$ power to detect a 2 -day reduction in LoS at a significance level of $p<0.05$. Variables between-groups were analysed using Students T-test with $95 \%$ confidence intervals, Fisher's exact test for dichotomous variables, the Mantel-Haenszel Chi-squared test for ordered categorical variables, the Chi-squared test for non-ordered categorical variables, and the Mann-Whitney $U$-test for continuous variables. The data were analysed using SPSS version 19.0 for Windows (SPSS Inc, Chicago, IL, USA).

\section{Results}

A total of 266 patients were enrolled in this study between September 2010 and November 2012. The control and intervention groups consisted of 138 and 128 patients, respectively. Baseline characteristics of the study cohort are shown in Table 1.

The majority of the patients were women (172 women vs. 94 men); the mean age was 66 years in the control group and 68 years in the intervention group. There were no significant differences between the groups in terms of baseline characteristics except that more patients were living in flats in the intervention group. Almost all patients were self-sufficient before surgery despite the troubling hip measured by the functional recovery scale.

The occurrence of low GSES and high TSK in the control and intervention groups is shown in Table 2. 
Table 1 Patient baseline data collected before surgery

\begin{tabular}{lll}
\hline Data & Control $n=138$ & gPCC \\
\hline Female/male & $89 / 49$ & $83 / 45$ \\
Mean age & 66 & 68 \\
Standard Deviation & 13,9 & 12 \\
Living & & \\
$\quad$ with someone & 90 & 68 \\
alone & 46 & 56 \\
Employment status & & \\
Employed & 32 & 33 \\
Retired & 84 & 79 \\
Disability pension & 16 & 5 \\
Other & 3 & 6 \\
Contact with relatives & & 120 \\
Weekly & 129 & 4 \\
Weekly to monthly & 6 & 2 \\
$<$ monthly & 2 & 4 \\
Home nursing & & 120 \\
Yes & 1 & \\
No & 132 &
\end{tabular}

Emergency medical alarm at home

$\begin{array}{lll}\text { Yes } & 15 & 9 \\ \text { No } & 97 & 113\end{array}$

Number of co-morbidities

$\begin{array}{lll}\text { Median } & 1 & 1 \\ \text { Min } & 0 & 0 \\ \text { Max } & 6 & 9\end{array}$

ASA grade

$\begin{array}{lll}1 & 36 & 22 \\ 2 & 75 & 69 \\ 3 & 27 & 16\end{array}$

Using naturopathic preparation

$\begin{array}{lll}\text { Yes } & 116 & 107 \\ \text { No } & 19 & 17\end{array}$

Type of living

$\begin{array}{lll}\text { Flat } & 62 & 74 \\ \text { House } & 75 & 52 \\ \text { Service flat } & 1 & 2\end{array}$

Need of assistance from relative

$\begin{array}{lll}\text { Yes } & 71 & 67 \\ \text { No } & 57 & 54\end{array}$

Need of community home help

$\begin{array}{lll}\text { None } & 120 & 115 \\ \text { Once a week } & 6 & 6 \\ \text { Daily or more } & 7 & 4\end{array}$

Table 1 Patient baseline data collected before surgery (Continued)

Assistive aids for personal use

such as pincers, seat cushions

and so on

Yes $\quad 46$

No 44

51

0.6

Pre-fracture independence ${ }^{\mathrm{b}}$

$\begin{array}{lll}80-100 \% & 132 & 117 \\ 60-79 \% & 3 & 7 \\ <60 \% & 3 & 3 \\ \text { Mean } & 92 & 92 \\ \text { SD } & 13 & 16\end{array}$

Type of walking aid

$\begin{array}{lll}\text { None } & 44 & 42 \\ \text { Crutches } & 64 & 54 \\ \text { Walking frame } & 14 & 19 \\ \text { Wheel chair } & 3 & 4\end{array}$

Previous hip replacement in contralateral hip

$\begin{array}{lll}\text { Yes } & 47 & 32 \\ \text { No } & 91 & 95\end{array}$

Feeling healthy

Yes

78

0.7

No

19

77

${ }^{\mathrm{a} C e d e r ~ s c a l e ~}$

$0.06{ }^{\mathrm{b}}$ Functional Recovery Scale [40]

*significant

The missing data for some of the variables were not regarded to impact the overall study results

gPCC Gothenburg person-centred care

0.1

Low GSES and high TSK scores were very common in both groups of patients scheduled for THA surgery around 1/3 had low GSES and about half had high fear of movement (Table 2).

The result was arranged as incremental distribution to make the result more visible. In the control group $30 \%$ had low GSES vs. $34 \%$ in the intervention group. Among patients who scored low on the GSES, there was a significant shift toward a shorter LoS in the intervention 1.6 days shorter than in the control group. The range was 6 days shorter in the intervention group compared to the controls (Table 3).

Surprisingly many patients had a high TSK, around $50 \%$ in both groups. Among patients who scored high on the TSK, there was a significant shift toward a shorter LoS in the intervention group compared with the control group. In the sub-group of patients with high TSK the LoS was shifted one step from increment $\operatorname{LoS} \geq 10$ days to increment LoS 6-9 days. However, the difference in LoS between the groups was large (2.43 days) and the variation among the controls showed by SD and 
Table 2 Occurrence of low GSES and high TSK in the entire study group of 266 patients

\begin{tabular}{|c|c|c|c|c|c|c|c|}
\hline & \multicolumn{3}{|c|}{ Control group $(n=138)$} & \multicolumn{4}{|c|}{ Intervention group $(n=128)$} \\
\hline & $n$ & Mean (SD) & Median (Min-Max) & $n$ & Mean (SD) & Median (Min-Max) & $P$-value \\
\hline GSES $\leq 29^{a}$ & $36(26 \%)$ & $25.3(4.2)$ & $27(11-29)$ & $40(37 \%)$ & $24.3(5.1)$ & $26(10-29)$ & 0.3 \\
\hline $\mathrm{TSK} \geq 40^{\mathrm{b}}$ & $70(52 \%)$ & $46.9(5.3)$ & $46(40-64)$ & $63(59 \%)$ & $43.2(5.5)$ & $45(40-60)$ & 0.4 \\
\hline
\end{tabular}

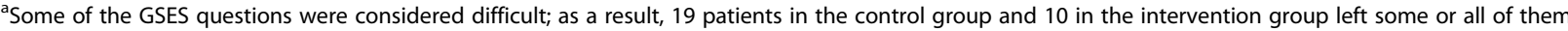
blank and therefore had to be excluded

${ }^{\mathrm{b}}$ Regarding the TSK, 8 patients in the intervention group did not answer all questions and had to be excluded

SD standard deviation, GSES general self-efficacy scale, TSK tampa scale of Kinesiophobia

range was a big. Patients in the control group who had high TSK, had the longest LoS and the highest mean seen in any of the sub-groups, almost 8 days.

There was a correlation between TSK and LoS indicating that high fear of movement is a predictor for LoS which can be influenced (Table 4).

In total $20 \%$ of all patients scored low on GSES and high on TSK, $17 \%$ in the control group vs. $21 \%$ in the intervention group. The number of days was reduced by more than 2 days in the intervention group relative to the control group $(p=0.028)$. There were almost twice as many patients in the increment $\operatorname{LoS} \leq 5$ days in the intervention group $(60 \%)$ compared to the controls (37 \%) (Table 5).

The ASA grading system is used by anesthetists for grading patients' physical health status (risk estimation) before surgery. In a simplified description the grades are ASA $1=$ normal health, ASA $2=$ mild systemic disease, ASA $3=$ Severe systemic disease [33].

In the standardized care group the LoS was predicted for all patients to be 4-5 days and the patients graded ASA 1 would be most likely to achieve that, however $29 \%$ did not manage that.

In the control group there was strong a significant correlation between age and ASA grade, age increased with risk $(p=0.01)$. A second strong correlation was found among the controls between ASA grade and LoS $(p=0.000)$ : the trend was that LoS was increasing with impaired health. These trends were not observed in the intervention group, where a large reduction in LoS was seen among ASA grade 3 patients compared with ASA grade 1 and 2 patients (Table 6).

\section{Discussion}

The main finding in the present study was that low GSES and high TSK scores were common in patients scheduled for THA surgery, around 30 and $50 \%$ respectively. The LoS for patients who had low GSES and high TSK scores was possible to affect. The hypothesis that a low self-efficacy and/or high fear of movement could disturb rehabilitation after surgery may be true. There is very little research connecting rehabilitation to GSES. In one study, patients' perceived self-efficacy was found to have a predictive value regarding their return to acceptable levels of physical activity and muscle function 1 year after knee ligament reconstruction [34]. Another study showed that self-efficacy significantly increased during the rehabilitation process [35].

The level of pain after THA could be perceived as very high initially [18]. Based on previous knowledge low self-esteem and perception of pain is a signal to be still could have a negative impact on postoperative rehabilitation [32, 34, 36]. If the start of rehabilitation is delayed the LoS will be prolonged. In studies of Fast-track care systems patients who can start their rehabilitation already on the day of surgery, they can be discharged on day two or three [37].

As part of the preoperative investigation, an anaesthesiologist assessed and graded patients into different

Table 3 Incremental distribution and overall LoS in patients with low GSES $(\leq 29)$

\begin{tabular}{|c|c|c|c|c|c|c|c|c|}
\hline \multicolumn{9}{|c|}{ Control Group N=119 } \\
\hline & \multicolumn{3}{|c|}{ LoS $\leq 5$ days } & \multicolumn{4}{|c|}{ LoS 6-9 days } & LoS $\geq 10$ days \\
\hline GSES $\leq 29$ & $n=36$ & \multicolumn{2}{|l|}{$15(42 \%)$} & \multicolumn{4}{|c|}{$14(39 \%)$} & $7(19 \%)$ \\
\hline \multicolumn{9}{|c|}{ Intervention group $N=118$} \\
\hline GSES $\leq 29$ & $n=40$ & $23(58 \%)$ & & \multicolumn{4}{|c|}{$14(35 \%)$} & $3(1 \%)$ \\
\hline \multicolumn{9}{|c|}{ Overall LoS in the groups with low GSES $\leq 29$} \\
\hline & & Mean LoS & SD & Range & Difference & \multicolumn{2}{|c|}{$95 \% \mathrm{Cl}$} & $P$-value \\
\hline Control Group & $n=36$ & 7.31 & 3.9 & 18 days & 1.60 & 0.16 & 3.15 & 0.03 \\
\hline gPCC Group & $n=40$ & 5.70 & 2.3 & 12 days & & & & \\
\hline
\end{tabular}

LoS length of stay, GSES general self-efficacy scale, gPCC Gothenburg person-centred care, SD standard deviation 
Table 4 Incremental distribution and overall LoS in patients with high TSK $(\geq 40)$

\begin{tabular}{|c|c|c|c|c|c|c|c|c|}
\hline \multicolumn{9}{|c|}{ Control Group N = 138} \\
\hline & \multicolumn{3}{|c|}{ LoS $\leq 5$ days } & \multicolumn{4}{|c|}{ LoS 6-9 days } & LoS $\geq 10$ days \\
\hline TSK $\geq 40$ & $n=70$ & \multicolumn{2}{|l|}{$35(50 \%)$} & \multicolumn{4}{|c|}{$21(30 \%)$} & $14(20 \%)$ \\
\hline \multicolumn{9}{|c|}{ Intervention group $N=120$} \\
\hline TSK $\geq 40$ & $n=63$ & \multicolumn{2}{|l|}{$36(57 \%)$} & \multicolumn{4}{|c|}{$25(40 \%)$} & $2(3 \%)$ \\
\hline \multicolumn{9}{|c|}{ Overall LOS in the groups with high TSK $\geq 40$} \\
\hline & & Mean & SD & Range & Difference & \multicolumn{2}{|c|}{$95 \% \mathrm{Cl}$} & $P$-value \\
\hline Control Group & $n=70$ & 7.91 & 6.4 & 41 days & 2.43 & 0.76 & 4.12 & 0.005 \\
\hline gPCC Group & $n=63$ & 5.48 & 2.2 & 12 days & & & & \\
\hline
\end{tabular}

LoS length of stay, TSK tampa scale of Kinesiophobia, gPCC, Gothenburg person-centred care, SD standard deviation

risk categories $(1-3)$ to ensure that the surgery is medically safe. In clinical settings, it is not uncommon to regard patients in ASA category 3 (increased risk) as possessing less resources compared with patients graded as ASA category 1 or 2 . In the present study, this was observed in the control group, where a correlation was found between LoS and ASA grade $(p=0.000)$. A larger reduction in LoS was seen with higher ASA grade in the intervention group, with the most dramatic reduction seen in ASA grade 3 patients. This was an important finding, indicating that it may be erroneous for health care professionals to assume that impaired health necessarily will interfere with patients' abilities to achieve effective rehabilitation. In PCC there is a focus on the patients' resources in order to detect possible deviations. A previous study evaluating patients with hip fractures found that, while the staff assumed that old age decreased patients' abilities to achieve an effective rehabilitation, this was demonstrated to be incorrect [5]. In the gPCC intervention, patients were seen as partners and were expected to provide knowledge about themselves that was important for their care. This was meant to decrease the risk of ascribing impaired abilities they did not have.

In the control group an unexpected correlation was found between ASA grade 3 and low GSES. ASA grade is not commonly discussed with patients, which make this correlation difficult to explain. However, in an earlier study on patients with health impairments such as diabetes, heart disease or hypertension requiring joint replacements, patients felt that the health professionals marginalised their well-being and only focused on the joint surgery [38]. The results of the present study suggest that the person-centred intervention provided to patients did have a positive effect on tangible outcomes (LoS).

Adding tools such as GSES and TSK appeared to be useful and an important part of or complement to the PCC assessment. The instruments accentuated the heterogeneity among patients and helped discern and address the unique needs of each patient. The RN was able to develop a personal health plan together with each patient based on the patient's narrative and the scores from the instruments. The health plan was a document meant to transfer information from the outpatient clinic to the hospital ward in order for RNs and physiotherapists to act upon. A previous study that evaluated patients who underwent THA found that shared decision-making and mutual respect did have positive effects on patient outcomes [39]. Higher quality of care, reduced postoperative pain, and improved physical function were also reported. The authors concluded that care focusing too much on flow and

Table 5 Incremental distribution and overall LoS in patients with both low GSES $(\leq 29)$ and high TSK $(\geq 40)$

\begin{tabular}{|c|c|c|c|c|c|c|c|c|}
\hline \multicolumn{9}{|l|}{ Control group } \\
\hline & \multicolumn{4}{|c|}{$\operatorname{LoS} \leq 5$ days } & \multicolumn{3}{|l|}{ LoS $6-9$ days } & LoS $>10$ days \\
\hline GSES $\leq 29$ and TSK $\geq 40$ & $n=24$ & \multicolumn{3}{|l|}{$9(37 \%)$} & \multicolumn{3}{|l|}{$10(42 \%)$} & $5(21 \%)$ \\
\hline \multicolumn{9}{|l|}{ Intervention group } \\
\hline GSES $\leq 29$ and TSK $\geq 40$ & $n=25$ & \multicolumn{3}{|l|}{$15(60 \%)$} & \multicolumn{3}{|l|}{$9(36 \%)$} & $1(4 \%)$ \\
\hline \multicolumn{9}{|c|}{ Overall LOS in the groups with low GSES $\leq 29$ and high TSK $\geq 40$} \\
\hline & & Mean LoS & SD & Range & Difference & \multicolumn{2}{|c|}{$95 \% \mathrm{Cl}$} & $P$-value \\
\hline Control Group & $n=24$ & 7.63 & 4.24 & 18 days & 2.15 & 0.24 & 4.05 & 0.028 \\
\hline gPCC Group & $n=25$ & 5.48 & 2.08 & 12 days & & & & \\
\hline
\end{tabular}

LoS: Length of stay; GSES: general self-efficacy scale; TSK: Tampa Scale of Kinesiophobia; gPCC: Gothenburg person-centred care; SD: standard deviation 
Table 6 Incremental distribution of LoS in patients by ASA grade (1-3)

\begin{tabular}{|c|c|c|c|c|c|c|c|c|c|}
\hline \multicolumn{10}{|c|}{ Control Group N=138 } \\
\hline & \multicolumn{5}{|c|}{ LoS $\leq 5$ days } & \multicolumn{3}{|l|}{ LoS 6-9 days } & LoS $\geq 10$ days \\
\hline ASA grade 1 & $n=37$ & \multicolumn{4}{|l|}{$26(70 \%)$} & \multicolumn{3}{|l|}{$9(24 \%)$} & $2(5 \%)$ \\
\hline ASA grade 2 & $n=83$ & \multicolumn{4}{|l|}{45 (54 \%) } & \multicolumn{3}{|l|}{$27(35 \%)$} & $11(13 \%)$ \\
\hline ASA grade 3 & $n=18$ & \multicolumn{4}{|l|}{$4(22 \%)$} & \multicolumn{3}{|l|}{$6(33 \%)$} & $8(44 \%)$ \\
\hline \multicolumn{10}{|c|}{ Intervention group $N=107^{\mathrm{a}}$} \\
\hline ASA grade 1 & $n=21$ & \multicolumn{4}{|l|}{$14(67 \%)$} & \multicolumn{3}{|l|}{$7(33 \%)$} & 0 \\
\hline ASA grade 2 & $n=61$ & \multicolumn{4}{|l|}{$35(57 \%)$} & \multicolumn{3}{|l|}{$22(36 \%)$} & $4(7 \%)$ \\
\hline ASA grade 3 & $n=25$ & \multicolumn{4}{|l|}{18 (72 \%) } & \multicolumn{3}{|l|}{$2(28 \%)$} & 0 \\
\hline \multicolumn{10}{|c|}{ Overall LoS for patients with ASA grade 1} \\
\hline & & Mean LoS & SD & Range & Diff & Age $\bar{x}$ (Median) & \multicolumn{2}{|l|}{$95 \% \mathrm{Cl}$} & $P$-value \\
\hline Control Group & $n=37$ & 5.65 & 2.97 & 18 days & 0.84 & $57(58)$ & -0.58 & 2.26 & 0.28 \\
\hline gPCC Group & $n=21$ & 4.81 & 1.72 & 9 days & & \multicolumn{4}{|l|}{$67(64)$} \\
\hline \multicolumn{10}{|c|}{ Overall LoS for patients with ASA grade 2} \\
\hline & & Mean LoS & SD & Range & Diff & Age $\bar{x}$ (Median) & \multicolumn{2}{|l|}{$95 \% \mathrm{Cl}$} & $P$-value \\
\hline Control Group & $n=83$ & 6.65 & 3.81 & 25 days & 0.81 & $67(67)$ & -0.3 & 1.93 & 0.15 \\
\hline gPCC Group & $n=61$ & 5.84 & 2.52 & 13 days & & $76(78)$ & & & \\
\hline \multicolumn{10}{|c|}{ Overall LoS for patients with ASA grade $3^{\mathrm{b}}$} \\
\hline & & Mean LoS & SD & Range & Diff & Age $\bar{x}$ (Median) & \multicolumn{2}{|l|}{$95 \% \mathrm{Cl}$} & $P$-value \\
\hline Control Group & $n=18$ & 11.50 & 9.36 & 40 days & 6.78 & $73(73)$ & 2.94 & 10.62 & 0.001 \\
\hline gPCC Group & $n=25$ & 4.72 & 1.57 & 7 days & & $69(71)$ & & & \\
\hline
\end{tabular}

aThere were 21 missing values in the intervention group because the ASA grade was not documented in these patients' journals or on the anaesthesia form An analysis of the missing patients' characteristics did not show any significant differences compared with the other patients in the intervention group. Age range, 46-86 years; mean, 68 years LoS range, $2-8$ days; mean, 4.3 days; SD, 1.6

${ }^{\mathrm{b}} \mathrm{A}$ correlation was found between GSES and LOS in the control group $(p=0,000)$

LoS length of stay, ASA, American society of Anaesthesiologists' classification system, gPCC Gothenburg person-centred care, SD standard deviation

pathways cannot replace relational communication and the partnership between health care professionals and patients [39].

\section{Limitations}

The study was conducted using a quasi-experimental prospective design in which consecutive patients in an intervention group were compared with patients in a control group receiving the usual care. This design was used primarily to avoid to the difficulty of having staff work with two care systems simultaneously. A disadvantage of this design is that it precludes evaluation of the true effects of an intervention; i.e., it is not possible to definitively conclude whether between-group differences occur because of the intervention itself or secondary to other unknown factors. However, since there are few circumstances under which non-RCT designs can yield reliable estimates of effect, conclusions from such studies, as ours, should be made with caution. Although random assignment was not applied, the control and intervention groups in this study were recruited according to the same protocol. In order to strengthen the study design a large number of clinical and sociodemographic variables were compared between groups.
In order to be informed of important decisions or changes that could have a favorable or unfavorable influence on the study, a study nurse participated in meetings with the surgeons and also in other important meetings. No such decisions occurred during the time for the study. During the intervention, recruitment stopped for several months because of the summer closedown and a shortage of nurses. However, these interruptions did not appear to cause bias in any of the measured variables.

\section{Conclusion}

The GSES instrument and the TSK instrument were found useful as tools to detect vulnerable patients and the instruments enabled the development of individualised, person-centred rehabilitation plans. By giving patients, with low self-efficacy and/or high fear of motion, individual support and attention regarding the surgical procedure and the rehabilitation it seem to be possible to reduce their hospital length of stay. Finally, we found that patients with impaired health (i.e., ASA grade 3) had a significant correlation with low GSES. Probably these patients can gain the most from an intervention such as this. 


\section{Relevance to clinical practice}

In the present study, awareness of the patients' who report low self-efficacy and high levels of fear of movement can help RNs tailor care more effectively in person-centred health plans. Our results suggests that short questionnaires like the GSES and TSK could be used routinely for planning the rehabilitation after THA surgery and likely for other surgical procedures as well, the ASA classification assigned by the anaesthetists is not a useful tool to predict patients' resources for rehabilitation or hospital LoS. The study was quasi experimental and more studies are needed to confirm our results.

\section{Acknowledgements}

Special thanks to the osteoarthritis group of the Rheumatic Union's Gothenburg branch, for helping and supporting the development of the intervention.

\section{Funding}

This study received support from the Institute of Health and Care Sciences at the University of Gothenburg, Sweden and from the Health and Medical Care Committee of the Regional Executive Board, Region Västra Götaland. This work was also supported by the Centre for Person-Centred Care at the University of Gothenburg (GPCC), Sweden. GPCC is funded by the Swedish Government's grant for Strategic Research Areas, Care Sciences [Application to Swedish Research Council nr 2009-1088].

\section{Availability of data and materials}

Not applicable.

\section{Authors' contributions}

LEO obtained funding for this study and was leader of the conceptualization and design of the study, data collection, analysis and drafting and revising the manuscript. EH participated in the data collection and the analysis of the data. LEO, EH and IE conceived of the study, and participated in its design and coordination and helped to draft the manuscript. All authors read and approved the final manuscript.

\section{Competing interests}

The authors declare that they have no competing interests.

\section{Consent for publication}

Not applicable.

\section{Ethics approval and consent to participate}

All patients were examined by an orthopaedic surgeon and an RN before surgery in the outpatient clinic, at which time they received oral and written information about the study and provided voluntary informed consent. The Regional Ethical Review Board in Gothenburg approved the study (Dnr: 275-10), and the investigation conformed to the principles outlined in the Declaration of Helsinki.

\section{Author details \\ ${ }^{1}$ Institute of Health and Care Sciences, Sahlgrenska Academy, University of Gothenburg, Box 457SE 40530 Gothenburg, Sweden. ${ }^{2}$ Gothenburg Centre for Person-Centred Care (GPCC), University of Gothenburg, Gothenburg, Sweden. ${ }^{3}$ Department of Orthopaedics, Sahlgrenska University Hospital, Gothenburg, Sweden.}

Received: 13 November 2015 Accepted: 30 August 2016

Published online: 09 September 2016

\section{References}

1. Ekman I, Hedman H, Swedberg K, Wallengren C. Commentary: Swedish initiative on person centred care. BMJ. 2015;350:160.

2. Van Royen $\mathrm{P}$, Beyer M, Chevallier P, Eilat-Tsanani S, Lionis C, Peremans L, Petek D, Rurik I, Soler JK, Stoffers HE, et al. The research agenda for general practice/family medicine and primary health care in Europe. Part 3. Results: person centred care, comprehensive and holistic approach. Eur J Gen Pract. 2010;16:113-9.

3. Ekman I, Swedberg K, Taft C, Lindseth A, Norberg A, Brink E, Carlsson J, Dahlin-Ivanoff S, Johansson IL, Kjellgren K, et al. Person-centered care-ready for prime time. Eur J Cardiovasc Nurs. 2011;10:248-51.

4. Ekman I, Wolf A, Olsson LE, Taft C, Dudas K, Schaufelberger M, Swedberg K. Effects of person-centred care in patients with chronic heart failure: the PCC-HF study. Eur Heart J. 2012;33:1112-9.

5. Olsson L, Karlsson J, Ekman I. Effects of nursing interventions within an integrated care pathway for patients with hip fracture. J Adv Nurs. 2007;58:116-25.

6. Olsson LE, Karlsson J, Ekman I. The integrated care pathway reduced the number of hospital days by half: a prospective comparative study of patients with acute hip fracture. J Orthop Surg Res. 2006;1:3.

7. Wolf D, Lehman L, Rosenzweig M, Friede S, Zullo T, Hoffman L. Can nurses impact patient outcomes using a patient-centered care model? J Nurs Adm. 2008;38:532-40.

8. Fors A, Ekman I, Taft C, Björkelund C, Frid K, Larsson M, Thorn J, Ulin K, Wolf A, K. S: Person-centred care after acute coronary syndrome, from hospital to primary care-a randomised controlled trial. International Journal of Cardiology 2015, doi:10.1016/.ijcard.2015.03.336.

9. Bandura A. Self-efficacy: The exercise of control. New York: W.H. Freeman; 1997.

10. Bandura A. Guide for constructing self-efficacy scales. Self-efficacy beliefs of adolescents. 2006;5.

11. Bandura A. Perceived self-efficacy in cognitive development and functioning. Educ Psychol. 1993;28:117-48.

12. Arnstein P. The mediation of disability by self efficacy in different samples of chronic pain patients. Disabil Rehabil. 2000;22:794-801.

13. Turner JA, Ersek M, Kemp C. Self-efficacy for managing pain is associated with disability, depression, and pain coping among retirement community residents with chronic pain. J Pain. 2005;6:471-9.

14. Denison E, Åsenlöf P, Lindberg P. Self-efficacy, fear avoidance, and pain intensity as predictors of disability in subacute and chronic musculoskeletal pain patients in primary health care. Pain. 2004;111:245-52.

15. Woby SR, Urmston M, Watson PJ. Self-Efficacy mediates the relation between pain-related fear and outcome in chronic low back pain patients. Eur J Pain. 2007;11:711-8.

16. Khan RS, Ahmed K, Blakeway E, Skapinakis P, Nihoyannopoulos L, Macleod K, Sevdalis N, Ashrafian H, Platt M, Darzi A. Catastrophizing: a predictive factor for postoperative pain. Am J Surg. 2011;201:122-31.

17. Quartana P, Campbell CM, Edwards RR. Pain catastrophizing: a critical review. Expert Rev Neurother. 2009;9:745-58.

18. Joelsson M, Olsson LE, Jakobsson E. Patients' experience of pain and pain relief following hip replacement surgery. J Clin Nurs. 2010;19:2832-8.

19. Dolin S, Cashman J, Bland J. Effectiveness of acute postoperative pain management: I. Evidence from published data. Br J Anaesth. 2002;89:409-23.

20. Pöpping D, Zahn P, Van Aken H, Dasch B, Boche R, Pogatzki-Zahn E. Effectiveness and safety of postoperative pain management: a survey of 18 925 consecutive patients between 1998 and 2006 (2nd revision): a database analysis of prospectively raised datat. Br J Anaesth. 2008;101:832-40.

21. Costal LCM, Maherl CG, MCAuleyl JH, Hancockl MJ, Smeetsl RJ. Self-efficacy is more important than fear of movement in mediating the relationship between pain and disability in chronic low back pain. Eur J Pain. 2011;15:213-9.

22. Robinson JP, Theodore BR, Dansie EJ, Wilson HD, Turk DC. The role of fear of movement in subacute whiplash-associated disorders grades I and II. Pain. 2013;154:393-401.

23. Vlaeyen JW, Kole-Snijders AM, Boeren RG, Van Eek H. Fear of movement/(re) injury in chronic low back pain and its relation to behavioral performance. Pain. 1995;62:363-72.

24. Leeuw M, Goossens ME, Linton SJ, Crombez G, Boersma K, Vlaeyen JW. The fear-avoidance model of musculoskeletal pain: current state of scientific evidence. J Behav Med. 2007;30:77-94.

25. Ayers DC, Franklin PD, Trief PM, Ploutz-Snyder R, Freund D. Psychological attributes of preoperative total joint replacement patients: implications for optimal physical outcome. J Arthroplast. 2004;19:125-30.

26. Rolfson O, Dahlberg L, Nilsson J-Å, Malchau H, Garellick G. Variables determining outcome in total hip replacement surgery. J Bone Joint Surg Br Vol. 2009:91:157-61.

27. Rolfson O, Kärrholm J, Dahlberg L, Garellick G. Patient-reported outcomes in the Swedish Hip Arthroplasty Register Results of a nationwide prospective observational study. J Bone Joint Surg Br Vol. 2011;93:867-75. 
28. Olsson L, Karlsson J, Berg U, Kärrholm J, Hansson E. Person-centred care compared with standardised care for patients undergoing total hip arthroplasty. J Orthop Surg Res. 2014;9:1-7.

29. Swedish version of the general self-efficacy scale. [http://userpage.fu-berlin. de/ health/swedish.htm]. Accessed 10 June 2014.

30. SPSS raw data with 18,000 participants [http://userpage.fu-berlin.de/health/ selfscal.htm]. Accessed 10 June 2014.

31. Lundberg M. Kinesiophobia : various aspects of moving with musculoskeletal pain. Göteborg: Göteborg University, Department of Orthopaedics, Institute of Clinical Sciences, The Sahlgrenska Academy at Göteborg University; 2006. Doctoral thesis.

32. Lundberg MKE, Styf J, Carlsson SG. A psychometric evaluation of the Tampa Scale for Kinesiophobia_from a physiotherapeutic perspective. Physiother Theory Pract. 2004;20:121-33.

33. ASA Physical Status Classification System [http://www.asahq.org/resources/ clinical-information/asa-physical-status-classification-system]. Accessed 10 June 2014.

34. Thomeé $P$, Währborg $P$, Börjesson M, Thomeé R, Eriksson Bl, Karlsson J. Selfefficacy of knee function as a pre-operative predictor of outcome 1 year after anterior cruciate ligament reconstruction. Knee Surg Sports Traumatol Arthrosc. 2008;16:118-27.

35. Thomeé $P$, Währborg $P$, Börjesson $M$, Thomeé R, Eriksson B, Karlsson J. Selfefficacy, symptoms and physical activity in patients with an anterior cruciate ligament injury: a prospective study. Scand J Med Sci Sports. 2007;17:238-45.

36. van den Akker-Scheek I, Stevens M, Groothoff JW, Bulstra SK, Zijlstra W. Preoperative or postoperative self-efficacy: Which is a better predictor of outcome after total hip or knee arthroplasty? Patient Educ Couns. 2007;66:92-9.

37. Andersen LØ, Gaarn-Larsen L, Kristensen B, Husted H, Otte K, Kehlet H. Subacute pain and function after fast-track hip and knee arthroplasty. Anaesthesia. 2009;64:508-13.

38. Williams A, Dunning T, Manias E. Continuity of care and general wellbeing of patients with comorbidities requiring joint replacement. J Adv Nurs. 2007:57:244-56.

39. Gittell JH, Fairfield KM, Bierbaum B, Head W, Jackson R, Kelly M, Laskin R, Lipson S, Siliski J, Thornhill T, Zuckerman JD. Impact of relational coordination on quality of care, postoperative pain and functioning, and length of stay: a nine-hospital study of surgical patients. Med Care. 2000;38: 807-19.

40. Zuckerman JD, Koval K, Aharonoff GB, Skovron ML. A functional recovery score for elderly hip fracture patients: II. Validity and reliability. J Orthop Trauma. 2000;14:26-30.

\section{Submit your next manuscript to BioMed Central and we will help you at every step:}

- We accept pre-submission inquiries

- Our selector tool helps you to find the most relevant journal

- We provide round the clock customer support

- Convenient online submission

- Thorough peer review

- Inclusion in PubMed and all major indexing services

- Maximum visibility for your research

Submit your manuscript at www.biomedcentral.com/submit

) Biomed Central 